\title{
Análisis de la situación del estado de la Gestión Integral de Residuos (GIR) en el cantón de Guácimo, Costa Rica
}

\author{
Analysis of the solid waste management \\ of Guacimo, Costa Rica
}

Rooel Campos-Rodríguez

Silvia Soto-Córdoba²

Campos-Rodríguez, R; Soto-Córdoba, S. Análisis de la situación del estado de la Gestión Integral de Residuos (GIR) en el cantón de Guácimo, Costa Rica. Tecnología en Marcha. Vol. 27, No I. Pág I | 4-124

\footnotetext{
Profesor-Investigador. Escuela de Agronegocios. Instituto Tecnológico de Costa Rica. Costa Rica. Correo electrónico: rocampos@itcr.ac.cr.

2 Doctora en Ciencias Ambientales, Catedrática. Escuela de Ingeniería Ambiental. Instituto Tecnológico de Costa Rica. Costa Rica. Correo electrónico: ssoto@itcr.ac.cr.
} 


\section{Palabras claves}

Residuos sólidos; municipalidad de Guácimo; GIR; planes de manejo de RSM; aspectos políticos en la GIR.

\section{Resumen}

El objetivo de este artículo es mostrar los resultados del análisis de la gestión de los Residuos Sólidos Municipales (RSM), en la Municipalidad de Guácimo, localizada en Limón, Costa Rica. Esta Municipalidad no dispone de suficiente cantidad de información básica, para implementar su sistema de gestión integral de residuos sólidos (GIR), por esta razón, esta investigación provee los insumos necesarios para poder iniciar este proceso de construcción del GIR. Para esto, se recopiló la información bibliográfica disponible de la zona, se desarrollaron los instrumentos de captura de información, se entrevistaron los principales actores sociales, se realizaron visitas de campo y se analizó toda esta información, de forma que se logró sistematizar y organizar en los siguientes tópicos: Gestión administrativa de los residuos sólidos (porcentajes de cobertura de recolección, planes de gestión, camiones recolectores y rutas, limpieza de parques y vías, botadero que utiliza la municipalidad), Actores Sociales (centros de recuperación de residuos sólidos y acciones municipales). La Municipalidad de Guácimo maneja sus residuos sólidos con poca planificación, atendiendo más bien las urgencias que se presentan el día a día, con un presupuesto insuficiente para garantizar un servicio de calidad que proteja el ambiente, por lo que genera grandes impactos ambientales tanto en los procesos de recolección, transporte y disposición, siendo este último el de mayor impacto, ya que los RSM son enterrados en una finca sin ningún tipo de protección ambiental.

Este artículo, analiza la interacción entre los factores políticos, organizacionales, culturales, la administración de los residuos sólidos municipales y su impacto en el ambiente, con el fin de proveer algunas alternativas para mejorar la GIR. Se espera que este esfuerzo sirva para poder mejorar e implementar el sistema de gestión integral de residuos sólidos para la Municipalidad de Guácimo.

\section{Key Words}

Solid waste, Guacimo Municipality; SWM management plans; political aspects of ISWM.

\begin{abstract}
The aim of this paper its shows the results about the analysis of the solid waste management in the "Municipalidad of Guacimo" located in Limón, Costa Rica. The Municipalidad of Guacimo doesn't have the basic records and enough information that is necessary for improve the management of the solid waste. Because of that, this investigation provides the inputs for begin to design the solid waste management for the Municipalidad of Guacimo.
\end{abstract}

We search quotes bibliographic about the situation and characteristics of the management of solid waste in Guácimo, we develop the methodology for research and obtain primary information, interview the principal people that work with the solid waste in the Municipalidad of Guacimo and gathering the most important information. We sort and systematize the information about the administration for cleaning the streets and municipal parks, the administration of the collect the solid waste from the streets, schedule and routes of collection, operation of the landfill and the state of the recycle centers. The Guacimo Municipality doesn't handle appropriately their solid waste, the administration doesn't have proposals for the adequate management of the solid waste, the budget isn't enough for collect, transport and disposable the solid waste considering the optimal methods for secure environmental protection, instead, the Municipality contributes to increase the environmental contamination in the area, because the solid waste are dumping in inappropriate site.

In this paper, we analyze the interaction among of the politics, organizational culture, management and municipal administration, it's our wish to provides different alternatives and solutions for improve the waste management in the Municipalidad of Guacimo. 


\section{Generalidades}

El cantón de Guácimo es el sexto cantón de la provincia de Limón y está ubicado en Costa Rica. Las coordenadas geográficas medias son $10^{\circ} 12^{\prime} 13^{\prime \prime}$ latitud norte y $83^{\circ} 37^{\prime} 30^{\prime \prime}$ longitud oeste (figura I), cuenta con 576,48 kilómetros cuadrados de extensión y una población de 4I 266 habitantes según el Instituto Nacional de Estadísticas y Censos (INEC, 20| I)

Está dividido en cinco distritos: Guácimo, Mercedes, Pocora, Río Jiménez y Duacarí. Los límites del cantón son: al norte y al oeste el cantón de Pococí, al sur el cantón de Turrialba, Provincia de Cartago y al este Siquirres (PNUD, FOMUDE, 2009).

En la página oficial de la Contraloría General de la República, (201 I) se ubica al municipio de Guácimo en la posición 76, asignándole una nota en aspectos de saneamiento ambiental de 29,9\%. Para calcular estos porcentajes la Contraloría utiliza los siguientes criterios de calificación: la recolección de residuos, el depósito y tratamiento de estos y el aseo de vías y sitios públicos (Contraloría General de la República Costa Rica, 20l I). En este mismo estudio, se indica que la Municipalidad de Guácimo, no cuenta con estudios de generación ni de composición de residuos sólidos, ni ha determinado el costo por tonelada métrica de los RSM tratados. También se indica que para el año 20 I I, esta municipalidad tuvo ingresos reales por US \$223000 correspondientes al servicio de recolección de residuos, sin embargo, el gasto real del servicio de recolección de residuos ascendió a US \$285000, lo que provocó un déficit estimado de US \$62 000 al año. Adicionalmente, solo se invirtieron US $\$ 270$ en maquinaria, equipo y mobiliario lo que representa tan solo un $0,12 \%$.

Según él (INEC, 20 I I), la cantidad de viviendas ocupadas ascendió a 11,797 , con un promedio de 3,5 habitantes por unidad habitacional. Para el año 201 I, en el cantón de Guácimo el 6,32\% de la población no tenía la educación primaria completa, este índice es superior al nacional de 4,40\%, lo que revela el grado de rezago del cantón.

\section{Metodología}

Se realizaron entrevistas semiestructuradas con el fin de recabar la siguiente información primaria: situación actual de la administración de los residuos sólidos en el Cantón, estado de la limpieza de vías y parques, identificación de las rutas y horarios de recolección de residuos, estado del manejo del botadero municipal, existencia y tipos de centros de recuperación de materiales y los principales actores sociales del cantón. Estas entrevistas se

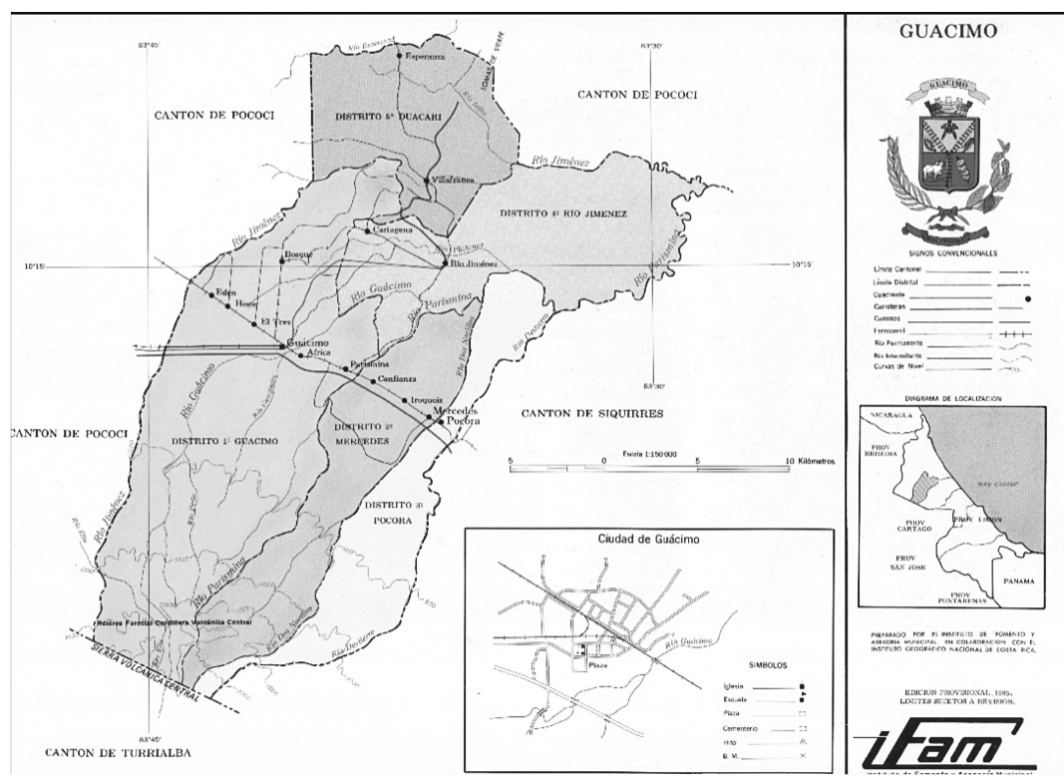

Figura I. Mapa del Cantón de Guácimo

Fuente: (http://ccp.ucr.ac.cr/bvp/mapoteca/CostaRica/generales/atlas_cantonal_1 984/87-Guacimo.pdf) 
les aplicaron al: I) grupo de trabajo denominado "Ambiente Sano, Guácimo Recicla" del Comité Plan de Residuos Sólidos (PRESOL) anillo central de Guácimo, conformado por representantes del Ministerio de Salud, Vice alcaldía municipal, síndicos, regidores y el encargado de saneamiento ambiental de la Municipalidad. (Sánchez Bonilla, 20II) 2) el personal técnico y operativo de la Municipalidad, 3) el Concejo Municipal y la Alcaldía. Las entrevistas se realizaron entre el mes de marzo 2012 hasta marzo del 2013

Adicionalmente, se realizaron visitas para corroborar la información contenida en las entrevistas. Se realizó búsqueda y análisis de información secundaria en diferentes páginas oficiales del país. Con todos estos insumos se analizó la información y se establecieron algunas tendencias y estimaciones que se brindan en este artículo.

\section{Resultados}

\section{Gestión Administrativa}

\section{a) Porcentajes de cobertura de recolección}

Según los resultados del censo del año 201 I realizado por el (INEC, 20II), el 70\% de la población en Guácimo utilizan el camión recolector municipal para disponer sus Residuos Sólidos (RS), mientras que el $20 \%$ los queman, y el restante los bota en lotes baldíos, ríos quebradas o los entierran. Al contrastar estos datos estadísticos, con la información del número de abonados que maneja la Municipalidad de Guácimo, se observa que solo un 65\% (7 723 viviendas) contribuye con el pago del servicio de recolección, de forma que la municipalidad le recolecta a cerca de un 5\% de viviendas de más que no pagan por el servicio. En campo se logra observar esta práctica, ya que el camión recolector no logra discriminar entre las bolsas provenientes de los abonados que si pagan por el servicio, y aquellos que aprovechan la situación de la falta de controles y fiscalización. Es común observar en los días de recolección, que algunos vecinos colocan sus bolsas en los puntos de colecta.

Otra práctica que se observa en Guácimo, es la contratación de servicios de recolección privados, esto no pudo visibilizarse en la encuesta del INEC, al no poseer esta opción dentro de su banco de respuestas. Los materiales recolectados mediante esta modalidad, son enviados al vertedero que también es privado, en el mejor de los casos, pero no se tiene seguridad del destino final de estos materiales.

Es por ello que se determina que la forma de eliminación de RS en el cantón de Guácimo es la siguiente: $70 \%$ de las viviendas utilizan el camión recolector, de las cuales un 5\% no paga por el servicio, un porcentaje indeterminado, utiliza los servicios privados de recolección y otro porcentaje también indeterminado, quema, entierra o tira los RS en lotes baldíos o en los ríos. Este estilo de disponer los residuos sólidos, hace complejo el manejo de los mismos, ya que erradicar estas prácticas implica conflictos de orden económico y social. Estos elementos deben incorporarse en los planes de GIRS que elabore la municipalidad como aspectos críticos y urgentes de resolver.

\section{b) Planes de Gestión}

La municipalidad de Guácimo no cuenta con un Plan integral para el manejo de los residuos sólidos, el cual es obligatorio según la Ley 8839 sobre Gestión Integral de Residuos ( Asamblea Legislativa, 2010) y el manual para la elaboración de los planes. (Programa Competitividad y Medio Ambiente (CYMA), 2008). En la municipalidad se tiene solo un funcionario dedicado al saneamiento ambiental, que no cuenta con educación formal en el tema y ha tenido que irse capacitando sobre la marcha, por sus propios medios y sin contar con un plan de capacitación municipal. Este colaborador se dedica a tiempo completo a: fiscalizar el vertedero municipal, inventariar los botaderos clandestinos, administrar y velar por el mantenimiento de los camiones recolectores, es jefe del personal de recolección y de limpieza de vías y miembro del comité PRESOL, responde directamente al Alcalde.

\section{c) Camiones recolectores y rutas}

El Cantón solo dispone de dos camiones recolectores con una capacidad de 9 y I I Toneladas con una antigüedad de 12 años (figura 2), estos camiones no cuentan con sistemas de contención de lixiviados, siendo común la práctica de verterlos directamente en las calles. Tampoco cuentan con aire acondicionado y las ventanas están trabadas, debido a las elevadas temperaturas de la zona (promedio $32{ }^{\circ} \mathrm{C}$ ), los choferes se agotan y tienen que estar siendo relevados, esto es un peligro inminente por 

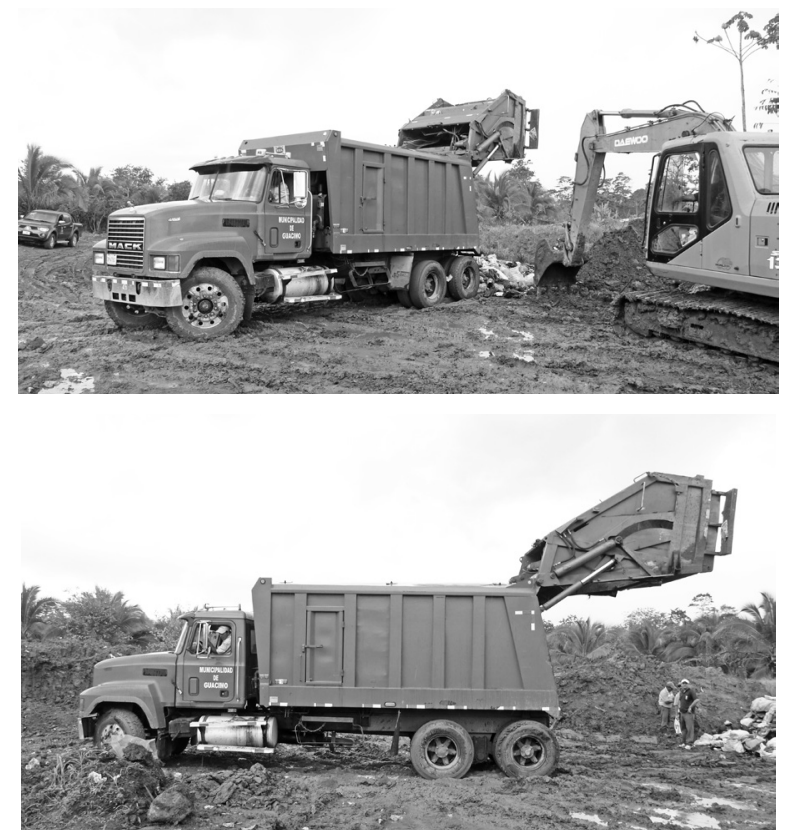

Figura 2: Camión recolector municipal en el Vertedero de Guácimo (tomada febrero 20।3)

una condición que es fácil de resolver. El servicio de recolección generalmente no cumple el horario establecido. No se tiene claridad de la eficiencia del uso de combustible que utilizan estos camiones, ya que los medidores están en mal estado, además de que no se tiene ningún tipo de control de distancias recorridas vs materiales recolectados. Otros insumos tales como llantas, repuestos, aceites, etc., no guardan relación con la calidad y estado de los vehículos, ya que se invierten muchos recursos en estos insumos y de manera generalizada al menos uno de los camiones presenta fallas mecánicas y problemas operacionales, por lo que esto obliga a trabajar en dos turnos de 6:00 am a 12:00 md y de 12:00 md a 6:00 pm, con un solo camión lo que disminuye la vida útil de estos, aumenta los costos operativos y la huella de carbono.

Las rutas de recolección se han establecido sin ningún tipo de estudio de carácter técnico, responden a las necesidades particulares de los operarios, de los vecinos, del alcalde, o bien responden a urgencias en el momento. Por tanto, no se optimiza el uso de combustible, no se cumplen con los horarios de recolección, no existe la planificación en este tema.

Se evidenció en la investigación que hasta la fecha no se han realizado estudios de seguridad ocu- pacional, cargas de trabajo, tiempos de descanso, peligrosidad, contaminación ni análisis de la situación de salud general de los trabajadores.

Encontramos que el diseño de las rutas no considera la carga de camiones, por lo que no se optimizan las recolectas, tampoco se considera el tránsito de los camiones sobre carreteras en mal estado, alamedas muy angostas o sitios donde transiten niños, tapas de alcantarillado inexistentes, o con un carpeteo muy delgado, lo que este tránsito podría provocar diversos accidentes que van desde daños de tuberías, accidentes de tránsito, daños a los camiones, etc. No se han realizado estudios del riesgo del transporte de materiales que inclusive pueden ser peligrosos por las características de la recolección no discriminada dentro de los vecindarios, ni de los tipos de materiales transportados, ni se tiene claridad del cumplimiento de las distancias y consumos de combustibles asociados, por estas razones no se puede planificar ninguna acción de mejora mientras no se dispongan de estos datos. Para tal fin, en los últimos años la Municipalidad ha contratado en forma intermitente una profesional en gestión ambiental, para que diseñe los instrumentos de control de aseos de vías, consumo de combustibles, cantidades depositadas en el vertedero, rutas de recolección, mantenimiento de vehículos, etc., usando como base las directrices de PRESOL, sin embargo, estos instrumentos a la fecha no se han validado ni puesto en marcha, por lo que el uso de estos recursos ha sido ineficiente.

El programa PRESOL contiene seis tareas, de las cuales, gracias a la contribución de esta profesional se pudo lograr al menos completar parcialmente la primera de estas.

\section{d) Limpieza de Parques y vías}

El aseo de parques y vías lo hacen dos funcionarios municipales contratados a tiempo completo, el servicio solo se brinda en el casco central de los distritos de Guácimo y Río Jiménez, no existe ningún plano o ruta definida de control del trabajo realizado, se calcula que entre ellos limpian un aproximado de nueve kilómetros lineales, dos veces por semana en el distrito de Guácimo y una vez por semana en Río Jiménez, no se sabe la cantidad de materiales que recolectan ni los tipos, solamente se conoce que los funcionarios colocan la basura en bolsas y 
la dejan en algunos puntos de común acuerdo para que el camión los recolecte, no utilizan el equipo de protección personal, aunque sí usan uniforme. Tampoco existen controles de ruta o trabajo, los trabajadores no marcan tarjeta por lo que se desconoce si cumplen el horario de trabajo, tienen una escolaridad muy baja, lo que dificulta el llenado de hojas de trabajo con información para rendir cuentas de sus servicios, a pesar de esto la Municipalidad no les ha brindado capacidad formal. Los vecinos y dueños de locales colindantes al parque central de Guácimo, colocan sus residuos sólidos en el mismo, aprovechando que este se limpia prácticamente todos los días, debido a que el mismo está frente al Municipio (Coronado, 2012).

No existe un buzón de quejas o registro de inconformidades, y aunque se han presentado algunas quejas esporádicamente, pero a estas no se les ha dado seguimiento.

\section{e) Botadero que utiliza la Municipalidad}

Para disponer los RSM, la Municipalidad de Guácimo contrata media hectárea en una finca privada en cuyo contrato se indica que es para "relleno sanitario". La misma se encuentra ubicada en el Distrito de Guácimo, Barrio Carambola, provincia de Limón. La Finca es parte del folio real 702650 I-000. El contrato indica que en la finca "se depositarán todos los desechos domiciliarios y de comercios no industriales recolectados, con excepción de los desechos de talleres, de jardines, llantas de camión u otros de similar condición, que recolecten en el cantón de Guácimo, para ello, el camión de recolección de basura propiedad de la Municipalidad o autorizados expresamente por esta, tendrán acceso sin restricción alguna a la finca dada en arrendamiento". Actualmente el contrato va desde el primero de marzo del 2013 hasta el 31 de diciembre del presente año, por un monto total de US \$7 722. En la práctica, la Municipalidad hace uso discrecional de varias fincas adyacentes posee aproximadamente 10 hectáreas. Estas fincas no cuentan con ningún tipo de infraestructura para atender la disposición de RSM. Para disponer los RSM solamente se cava una fosa de 5 metros de profundidad para depositarlos y luego se vuelve a tapar (figura 3).

Cuando se presentan lluvias importantes en la zona, se presenta el inconveniente que para llegar al vertedero se debe cruzar por una carretera de lastre y también se debe atravesar parte del río Bosque, el cual se desborda con la lluvia. Si por alguna razón el camión inició el recorrido y en el camino se desbordó el rio, es necesario devolverse hasta el plantel municipal, y ahí el camión se deja aparcado hasta que las condiciones de la ruta mejoren y se pueda regresar al botadero, mientras tanto no se brinda el servicio de recolección en las calles y la basura se continúa descomponiendo en el interior del camión.

Este vertedero ya ha sido intervenido por el Ministerio de Salud, pues no cumple con los requisitos mínimos para prestar este servicio, aun así, la Municipalidad de Guácimo continua enviando sus RS al lugar, amparándose en que no tienen otro sitio donde depositar la basura. El Ministerio de Salud realiza una visita mensual sorpresa, esto a

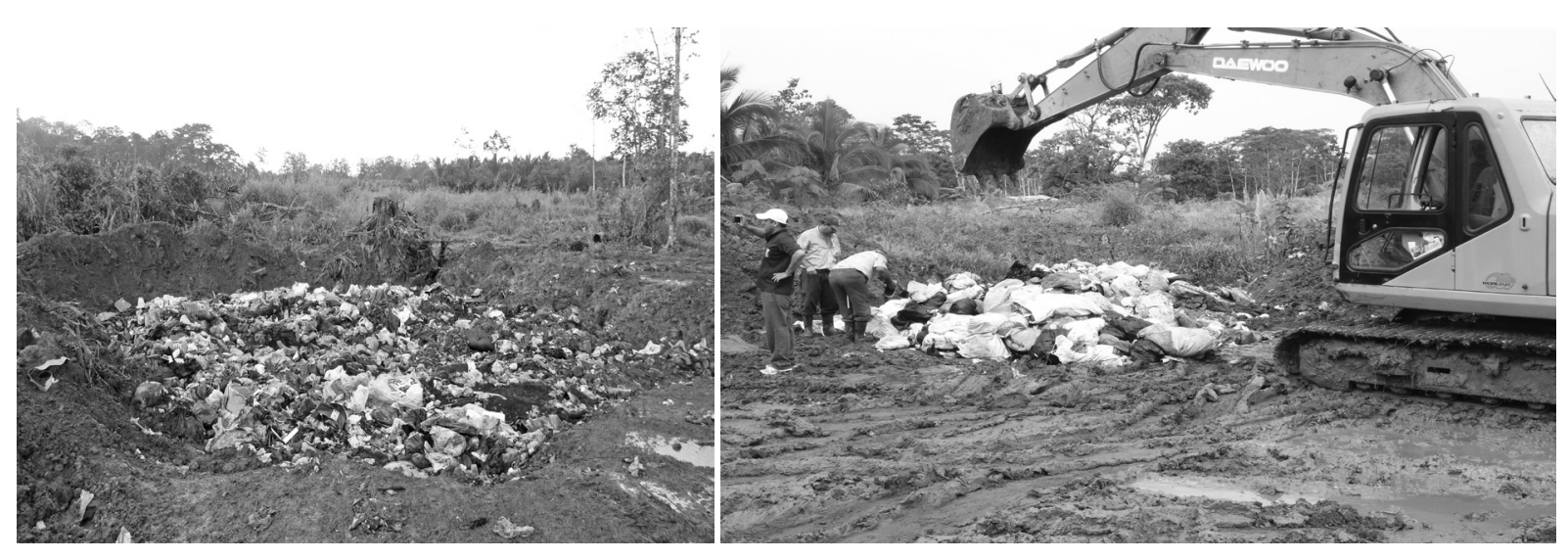

Figura 3. Fotografías del proceso de enterramiento de la basura en el vertedero municipal de Guácimo (tomada febrero 2013) 
petición del departamento de saneamiento ambiental. Desde el año 200 I se vienen dando múltiples quejas por este sitio e inclusive se hizo una denuncia ante el tribunal ambiental del Agua.

No existen controles de lixiviados, ni análisis de suelos, ni protección de capas freáticas, protección contra incendios, control de gases, control de roedores, seguridad privada, personal para controlar el ingreso de materiales, ni estadísticas de materiales depositados. El vertedero municipal funciona de lunes a viernes, recibe basura de todo tipo y cantidad, proveniente de otros cantones, empresas privadas como bananeras, piñeras e inclusive se tienen informes de haber recibido pinturas y disolventes orgánicos. Cuando los camiones particulares llegan a depositar los RS en el sitio aprovechan si existe una fosa abierta por la Municipalidad para depositar sus materiales, en caso contrario, los dejan sobre el suelo al descubierto, de forma que la retroexcavadora municipal debe darse a la tarea de enterrar los mismos aún cuando no hayan pagado por el servicio. Se ha observado que los costos por combustible por el uso de la retroexcavadora son inusualmente muy altos, pero esto se ha justificado por la necesidad mantener tapada toda la basura sea municipal o privada, aún cuando estos últimos no paguen por el servicio.

De la inspección visual al sitio se verificó la salida de gases desde el suelo, y temperaturas inusualmente altas que se determinan al abrir un hueco en el suelo. También existen reportes de bolsas en estado intacto luego de varios meses de haber sido enterradas.

No existen poblaciones cercanas al vertedero, solamente una piñera y fincas dedicadas a explotaciones agrícolas.

El dueño de la finca, una vez que los residuos son enterrados y ha pasado un tiempo prudencial $(6$ meses), se da a la tarea de sembrar en el sitio yuca, plátano, pipa, papaya, limones, entre otros, y posteriormente los vende al público en general, se desconoce si estos productos han sido contaminados con el material del vertedero. No se verifican en el sitio "buzos" o recolectores, debido posiblemente a la lejanía de centros poblacionales.

Actualmente no se tiene claridad de la cantidad de residuos depositados en el sitio, sin embargo, los autores utilizando la información de estudios pre- vios (EARTH), comunicaciones con el encargado de saneamiento ambiental (Coronado, 20I2), han estimado que en la operación de los últimos 10 años se han recibido cerca de 76000 toneladas de RS.

\section{Actores sociales}

\section{a) Centros de Recuperación de Residuos Sólidos}

Existen ocho Centros de Recuperación de materiales, pero Ministerio de Salud ha cerrado siete apegándose a la ley. El único que sigue trabajando de manera normal es el centro de recuperación de la Escuela del Trópico Húmedo (EARTH), que recolecta papel, cartón, plástico y vidrio de todo tipo.

Por su parte, los centros de acopio Carambola, Manos entrelazadas con el ambiente, Iroquois, Madre Tierra, Recicladora de Metal, Reproa S.A. y Coopeguacimeñas, están sin operación, por lo que no se tienen datos disponibles.

\section{b) Acciones municipales}

b.I Gestión de cobro

La municipalidad cuenta con cobros diferenciados en la recolección y servicio de limpieza de vías públicas y privadas, este cobro es mensual. Para realizar las clasificaciones y los cobros respectivos en teoría, se considera el volumen del material que generan los tipos de usuarios según tres clasificaciones: residencial, comercial-industrial e institucional-religioso. Para el sector residencial se asignan dos categorías según el volumen de RSM, de igual forma para el sector comercial-industrial se asigna cuatro categorías y finalmente para el sector institucional-religioso se asignan 2, los costos por recolección aumentan según la cantidad de material desechado. (cuadro I).

Debido a que la Municipalidad no cuenta con personal suficiente y solamente una romana para determinar el peso de los RSM, solo se aplican los cobros más bajos de cada categoría

La sostenibilidad del servicio de recolección de residuos según la contraloría (Contraloría General de la República Costa Rica, 20 I I) es de -27,7 \% lo que significa que el sistema no es sostenible y con el tiempo acumulará mayores problemas.

En el cuadro 2, se muestran los datos de morosidad acumulada para el año 2012, los mismos son históricos y en algunos casos se podría asumir como incobrables, debido a que algunas personas deudo- 
ras ya han fallecido, sin embargo, la municipalidad no tiene la estructura administrativa ni los recursos para depurar sus bases de datos rápidamente, además la estructura legal del país, principalmente, asociada a las políticas de la contraloría general de la república, no permiten ajustar estos flujos de caja al rubro de incobrables, lo que provoca que año con año la municipalidad reporte pérdidas en este rubro, y se desconozca la situación real de recursos para invertir en el manejo de los RSM (Coronado, 20I2).

\section{b.2 Convenios con universidades y ONGs}

La Universidad EARTH ha trabajado con la Municipalidad de Guácimo principalmente desarrollando estudios en Pocora y Mercedes (Camacho, Murillo, \& Yeomans, 200; Dicent, Yeomans, \& Argüedas, 2008; Abubacar, Acosta, \& Yeomans, 2008), la UNED firmó en el año 2010 un convenio de coo- peración para la capacitación en diferentes aspectos municipales (Ureña, 20l0) el cual vence en el 20I3, pero no ha impactado en el tema de los RSM. También se identifica una tesis con algunos resultados de opinión realizada en la Universidad para la Cooperación Internacional (Vallejo, 20 I I). El último convenio firmado por la municipalidad responde a los resultados de este trabajo, que permitirán a la misma contar con el análisis de la situación actual de los residuos sólidos y el estudio de generación y composición.

\section{b.3 Ejecución de presupuestos}

En la municipalidad de Guácimo se observó un procedimiento de asignación de partidas presupuestarias para los rubros de inversión y contratación de personal de apoyo, que incide directamente en la prestación del servicio de recolección y disposición

Cuadro I. Cobro por servicios de recolección y tratamiento de los RSM de la Municipalidad de Guácimo

\begin{tabular}{|c|c|}
\hline Tipo & Costo (US \$/mes) \\
\hline Sector residencial tipo I & 2,56 \\
\hline Sector residencial tipo 2 & 5,12 \\
\hline Comercial-Industrial tipo I & 5,12 \\
\hline Comercial-Industrial tipo 2 & 12,81 \\
\hline Comercial-Industrial tipo 3 & 25,63 \\
\hline Comercial-Industrial tipo 4 & 55,12 \\
\hline Institucional-Religioso tipo I & 3,84 \\
\hline Institucional-Religioso tipo 2 & 12,81 \\
\hline Servicios de Aseo de Vías y Sitios Públicos para las Residencias tipo 2 & 5,12 \\
\hline Limpieza de vías metro lineal & 0,24 \\
\hline
\end{tabular}

Fuente: Municipalidad de Guácimo

Cuadro 2. Morosidad del servicio de recolección de residuos y aseo de vías y sitios públicos de la Municipalidad de Guácimo

\begin{tabular}{|c|c|}
\hline Servicio & Total de morosidad acumulada a diciembre 20 I2 (US \$) \\
\hline Servicio de recolección de residuos & 420794 \\
\hline Servicio de aseo de vías y sitios públicos & 27368 \\
\hline TOTAL & 448162 \\
\hline
\end{tabular}

Fuente: Municipalidad de Guácimo, Gestión de Cobro. 
de los residuos sólidos. Los rubros de operación no presentan este problema.

El presupuesto por ley se asigna mediante el PAO (Plan Anual Operativo). El encargado de saneamiento ambiental, diseña el PAO y lo envía a la alcaldía, luego a contabilidad y finalmente al concejo municipal para su oportuna aprobación. Es común que no se aprueben ni los mínimos solicitados.

Es común observar una asignación tardía de algunas partidas que coadyuvan a la GIR lo que no permite que los mismos sean ejecutados, debido a que los controles administrativos, la ley de contratación pública y demás lineamientos, establecen una serie de procedimientos de compra, licitación y adjudicación, que son complejos y requieren de mucho tiempo.

Esta forma de administrar fondos provoca dos efectos, el primero es que todos los años la Municipalidad cuenta con un superávit que le permite al año siguiente financiar nuevamente los proyectos Esto provoca un rezago año con año pues no se hace inversión en el departamento de saneamiento ambiental, aunque en el plan operativo si se ve reflejada dicha inversión.

El segundo efecto, es la desmotivación de los funcionarios administrativos y operativos, ya que la baja ejecución presupuestaria no permite realizar proyectos necesarios para el departamento de saneamiento ambiental.

\section{Discusión y conclusiones}

La municipalidad de Guácimo es la llamada a brindar las pautas a seguir en el manejo, disposición y tratamiento adecuado de los residuos sólidos que se generen en su comunidad. Esta debe propiciar el trabajo conjunto entre los diferentes actores sociales, resolver los problemas de contaminación por tratamiento inadecuado, y brindar un servicio de calidad acorde a los ingresos.

La situación actual de la Municipalidad de Guácimo la coloca en una posición de alta vulnerabilidad en el manejo de los Residuos Sólidos. El problema es multivariado, incluye aspectos de decisión política, dificultades administrativas, problemas de planeamiento, falta de inversión y demás. Sin embargo, es el criterio de los autores, que si bien es cierto, existen algunas deficiencias económicas, este último no es el principal problema que incide en la mala gestión de los RS en Guácimo.

Dentro los problemas detectados en la municipalidad de Guácimo que inciden en la inadecuada GIR se tienen: la inexistencia de planes de gestión, la baja cobertura de recolección, la inexistencia de controles en la recolección, la ausencia de sitios de tratamiento apropiados, la falta de recursos, el uso poco efectivo de los mismos, la falta de una oficina de gestión ambiental y la necesidad de capacitación del personal, para que logren tomar decisiones públicas sostenibles acordes con la realidad y necesidad del cantón.

En la figura 4 se presenta un análisis comprensivo de los principales problemas y efectos según el nivel de responsabilidad municipal.

Debido a la inexistencia de planes de gestión, la municipalidad actúa conforme a las urgencias, solicitudes y demandas, por lo que no optimizan sus recursos, sobrecargan al personal, resuelven problemas de manera atomizada y no logran darle continuidad a los proyectos, por lo que en el tema de la gestión ambiental quedan debiendo, pues este es un tema de planificación a largo plazo y no se resuelve con acciones puntuales.

Obviamente, ante tal panorama es difícil realizar estudios, invertir en mejoras tecnológicas y optimizar el sistema, por lo que el primer paso para lograr tales mejoras es precisamente, informar, sensibilizar, generar actitudes y valores ambientales en el personal municipal para que se empoderen y realicen acciones ambientalmente positivas.

Si la municipalidad de Guácimo pretende ampliar el margen de cobertura del servicio de recolección de residuos y aumentar el porcentaje actual de $65 \%$, deberá indiscutiblemente de contar a la brevedad posible con los estudios de generación y composición del cantón, para así, poder realizar las proyecciones necesarias y plantear políticas públicas sostenibles en cuanto a las rutas de recolección, flotilla de recolección, personal, disposición final de los residuos, construcción y equipamiento de la oficina de gestión ambiental y capacitación general para el personal.

El accionar político de la municipalidad es fundamental para comprender el funcionamiento de cualquier proyecto que se ejecute, en los últimos años en Costa Rica han aparecido muchos grupos políticos, que 
polarizan o bien no permiten la toma de decisiones oportuna por cuestiones de cálculo electoral. En el caso de la Municipalidad de Guácimo, en la actualidad hay representación de varios grupos políticos como Partido Liberación Nacional (PLN, en el gobierno nacional y al cual pertenece el alcalde) en este momento mayoritario en la Municipalidad, el Partido acción ciudadana (PAC), el Movimiento Libertario $(\mathrm{ML})$ y Partido renovación costarricense (PRC).

Todos estos grupos son ideológicamente contrarios, van desde grupos neoliberales hasta izquierda y de índole religiosa, es común observar en las sesiones de consejo, gran cantidad de discusiones, muchas veces infructuosas y por cuestiones poco productivas. Cada grupo política busca sostener su punto de vista y se utilizan muchas horas buscando culpables a las múltiples acciones inconclusas que hay en la municipalidad. Este accionar atrasa la toma de decisiones, no permite la oportuna fiscalización y control, y es muy costoso para el municipio, tanto en términos económicos como de oportunidad y desarrollo.

El 63\% de los síndicos y regidores y también el alcalde, solo cuentan con la primaria completa, a pesar de ser personas muy inteligentes y con gran liderazgo, esta carencia educativa incide negativa- mente en algunas decisiones de carácter técnico, por la misma complejidad de las mismas, ya que se ve como un desperdicio la inversión de recursos en la planificación, la fiscalización, los controles, la compra de vehículos, el uso de tecnología, la inversión en profesionales especializados, la compra de equipo de cómputo, la inversión en capacitación del personal, etc.

Si el municipio de Guácimo desea resolver sus problemas de GIR debería considerar las siguientes experiencias positivas de otros países y municipios:

I. La toma de decisiones técnicas debe realizarla un ente técnico y no debe estar supeditada a los vaivenes políticos, ya que es un asunto de largo plazo y no puede estarse improvisando según cada administración.

Contar con una oficina de gestión ambiental puede ser algo costoso en una primera etapa, por lo que una excelente opción es construir alianzas con universidades para la capacitación y asesoramiento, contar con la pasantía de estudiantes de último nivel que desarrollen tesis en temas específicos para la construcción del Programa GIR. Otra opción es contratar consultores privados para actividades específicas

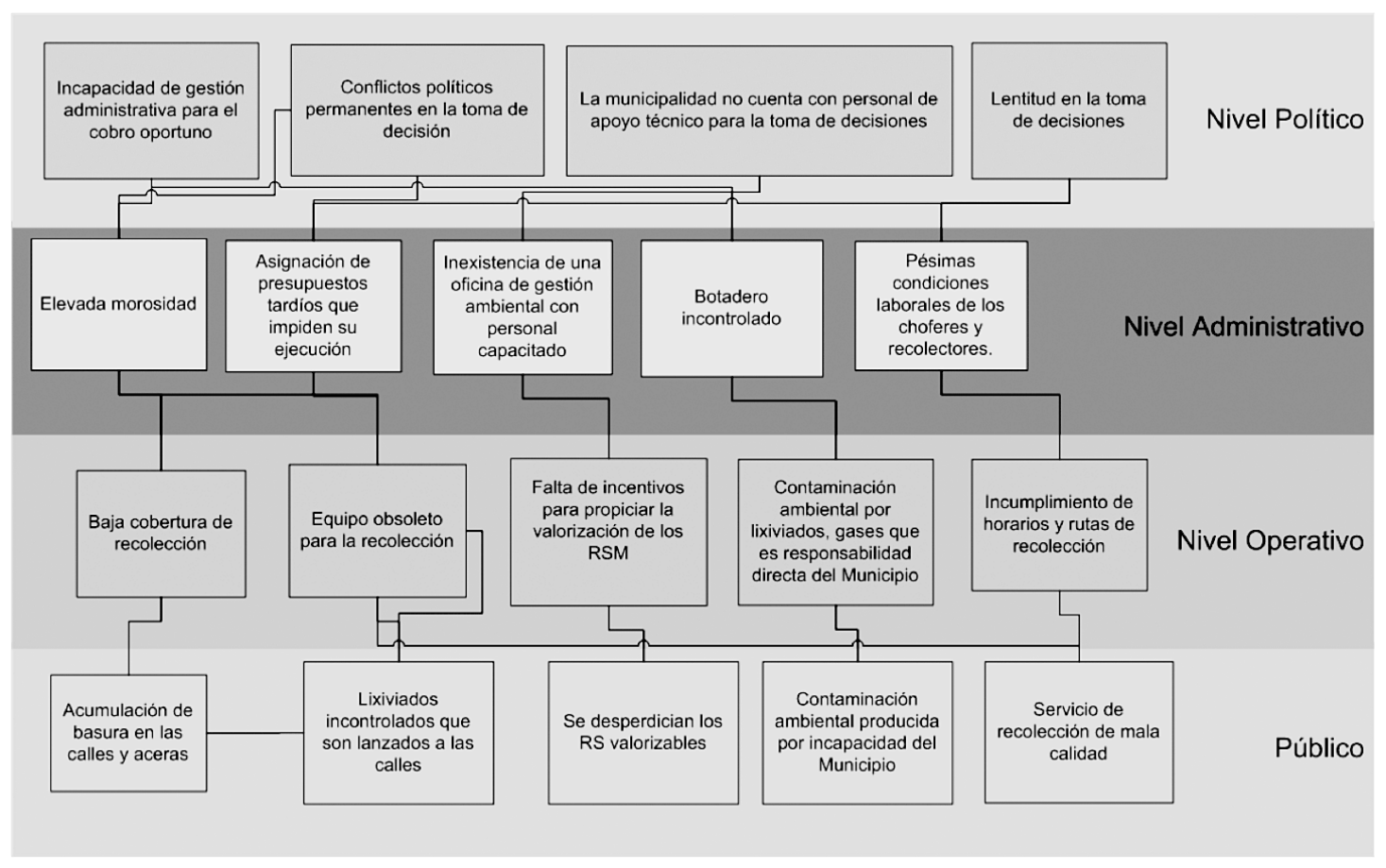

Figura 4. Relación de causas y efectos y sus problemas en el caso de la GIR de la Municipalidad de Guácimo. 
bien definidas, también se puede contar con profesionales y equipo de planta, lo cual le da al proceso mayor fortaleza y sostenibilidad, y finalmente, el municipio puede establecer alianzas con otras municipalidades para contar con un grupo común de técnicos para atender estas acciones.

Al contar con este ente técnico la municipalidad podría resolver los problemas operativos más comunes como el incumplimiento de horarios, la falta de fiscalización de operarios, las condiciones de trabajo, las rutas y horarios de recolección, etc. logrando con esto mejorar el servicio que se ofrece a los abonados.

2. Los presupuestos de inversión no deben comprometerse para otras actividades del Municipio.

Esta práctica tan indeseable debe erradicarse del accionar político pues no resuelve los problemas, sino más bien va generando otros más complejos como la desmotivación del personal. Es imperativo que la municipalidad incorpore estos recursos para la inversión respectiva y así mejorar el servicio.

3. Es urgente resolver el problema del botadero municipal.

La municipalidad no puede convertirse en un generador de contaminación, si a la fecha el ministerio de salud no ha logrado el cierre del sitio, esta no debe ser la razón por la cual el municipio continúe con esta contaminante práctica.

4. La valorización de los residuos.

Es una obligación según la ley GIR, por lo cual, mientras no se logren resolver estos problemas anteriores, será imposible comenzar con esta etapa. Para esto, es necesario conocer la composición de los RSM mediante un estudio de composición, esta actividad podría ser abordada por el ente técnico que haya seleccionado la municipalidad de Guácimo.

\section{Agradecimientos}

A la Vicerrectoría de Investigación y Extensión del Instituto Tecnológico de Costa Rica, por el financiamiento del proyecto "Fortalecimiento de las actividades ambientales municipales mediante el apoyo en la planificación de la gestión integral de los residuos sólidos en el Cantón de Guácimo", Código $540|-| 43|-300|$.

\section{Bibliografía}

Asamblea Legislativa. (2010). Ley para la Gestión Integral de Residuos. Costa Rica.

Abubacar, I., Acosta, J., \& Yeomans, J. (2008). Gestión administrativa para un programa de manejo de desechos en comunidades rurales. Tierra Tropical, 4( I), 83- I I8.

Camacho, J., Murillo, J., \& Yeomans, J. (2008). Plan de negocios para la implementación de un centro de recuperación de materiales en Guácimo, Costa Rica. Tierra Tropical, 4(I), 119-162.

Contraloría General de la República Costa Rica. (Diciembre de 201 I).Sistema integrado de información municipal. Obtenido de http://cgrw0 I.cgr.go.cr/apex/f?p= | 42: I:3 | 9466424982207 |

Coronado, R. (28 de setiembre de 2012). Gestor Ambiental, municipalidad de Guácimo. (R. Campos, Entrevistador)

Dicent, Y., Yeomans, J., \& Argüedas, M. (2008). Modelo de manejo de desechos sólidos ordinarios para el distrito de Pocora en Costa Rica. Tierra Tropical, 4( I), 31-82.

INEC. (23 de Febrero de 20I I). INEC Costa Rica. Obtenido de http://www.inec.go.cr/Web/Home/GeneradorPagina.aspx

PNUD, FOMUDE. (2009). Plan de Desarrollo Humano, Guácimo. Costa Rica.

Programa Competitividad y Medio Ambiente (CYMA). (2008). Manula para la Elaboración de Planes Municipales de Gestión Integral de Residuos Sólidos. San José.

Sánchez Bonilla,Y. (20 I I). Tarea I: Unamos voluntades para hacer el Plan de Municipal de Gestión integral de Residuos Sólidos del Cantón de Guácimo. Costa Rica.

Ureña, S. L. (7 de setiembre de 2010). Universidad Estatal a Distancia. Obtenido de Acontecer: http://www. uned.ac.cr/acontecer/index.php? option =com content\&view=article\&id=36l: uned-presente-enguacimo-tras-firma-de-convenio\&catid=51:gestionuniversitaria\&ltemid $=76$

Vallejo, S. (20I I ). Diagnóstico de la gestión de los desechos sólidos generados en la comunidad de Guácimo de Limón para el cumplimiento de la ley 14423. San José: UCl. 